\title{
Detecting some factors affecting Salmonella typhimurium adhesion and inhibition by Saccharomyces boulardii
}

Salmonella التحري عن بعض العوامل المؤثرة على التصاق وتثبيط بكتريا

Saccharomyces boulardii بواسطة خميرة typhimurium

Wasan Abbood

College of Science /Baghdad University

وسن عبود حسون

كلية العلوم / جامعة بغداد

\begin{abstract}
Intibiotic sensitivity of Salmonella isolates was investigated, the isolates were sensitive to some antibiotics such as chloramphenicol, imipenem and most of them showed resistance to amoxicillin and naldixic acid. The hydrophobicity of Salmonella was investigated by applying BATH test (Bacterial Adherence To Hydrocarbons) using xylene. The range was between (21-90) \%, the results showed that five isolates were hydrophobic including sal10 isolate. The surface layer proteins (SLP)of sal10 showed the ability to act as agglutinins by applying haemagglutination test with and without $0.5 \%$ mannose, also the bacteria seemed to possess pili -type1 because of its' ability to agglutinate with human blood cells and yeast cells. The agglutination of the bacteria was inhibited in the presence of mannose.The isolate sal10 was adhesive to buccal epithelial cells in an average 52 cell/epithelial cell, while this average decreased to reach 24 cell/ epithelial cell in the presence of Saccharomyces boulardii which was able to inhibit 54\% of the bacterial adherance.
\end{abstract}

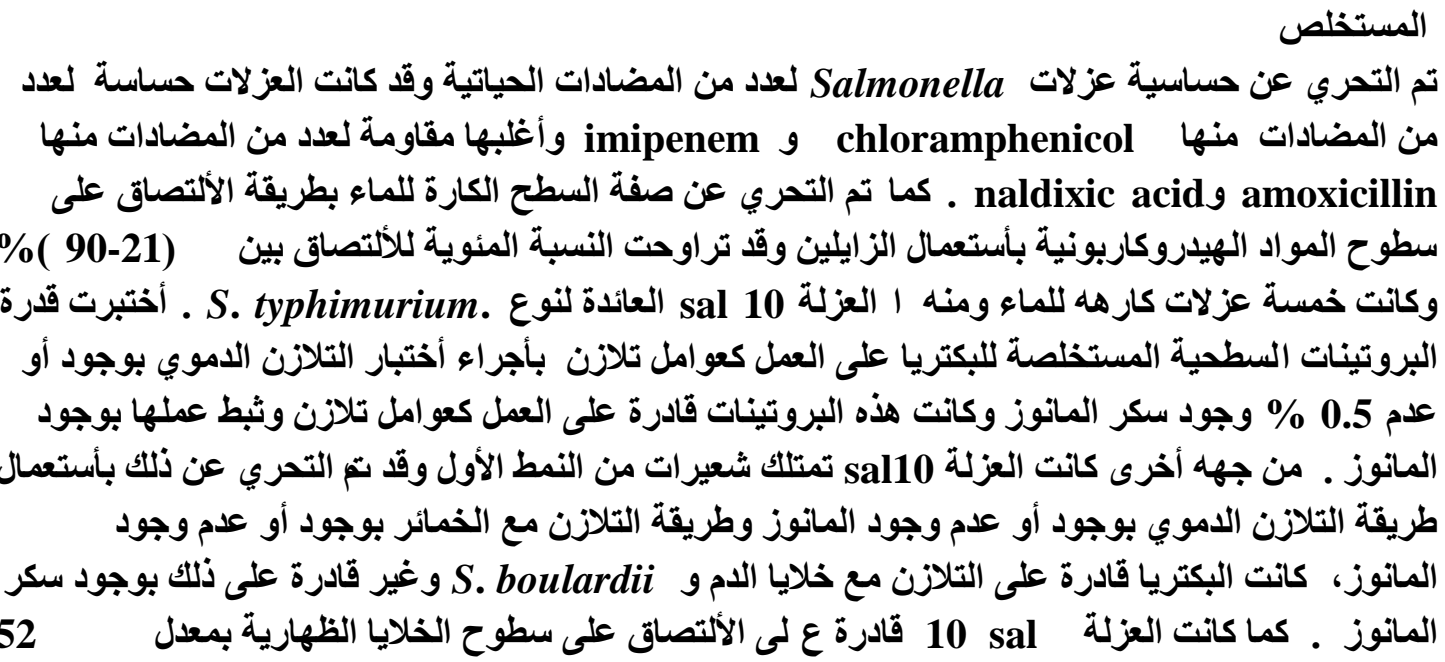

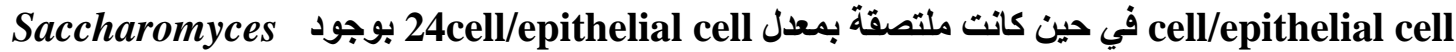

boulardii

\section{Introduction}

Salmonella spp. are pathogenic in both humans and animals, they can cause diseases ranging from gastroenteritis to typhoid fever depending on the serotype and the host [1]. Many investigations had been done upon Salmonella serotype Typhimurium in terms of pathogenesis in comparison with other serotypes [2]. Many investigations had been done upon factors which affect Salmonella adhesion: Hydrophobicity of cell surface of bacteria affects directly on its' adhesion, when bacteria is hydrophobic 
it is more adhesive [3]. Salmonella possess type-1 fimbriae which mediates attachment of bacteria to mannose receptors on mammalian cells [4]. Surface Layer Proteins (SLP) which is a paracrystalline surface also has a role in both adhesion and virulence of many bacteria [5]. As a result of the alarming increase in bacteria resistance including Salmonella (which may be due to the random use of antibiotics or the use of antibiotics in the therapy of animals and as growth promoters ) [6].Using living ingested microorganisms instead of antibiotics may play a role in prevention and treatment of intestinal infections including salmonellosis [7]. Saccharomyces boulardii is the only yeast with proven probiotic efficiency and clinical effects [8]. Many experimental effects of $S$. boulardii had been determined such as: inhibition of enteric pathogens, modulation of immune system, antiinflammatory effects [9]. This study aimed to examine the adhesion abilities of Salmonella by detecting its' cell surface characteristics which helps in understanding its' inhibition by $S$. boulardii a probiotics strain, this represent an important application in biotechnology in the present.

\section{Materials and methods}

\section{Isolation and characterization of Salmonella}

Twenty five isolates suspected to be Salmonella were obtained from the Teaching Laboratories of Medical City /Baghdad. These isolates were characterized as Salmonella by using biochemical tests [10]. APi 20 E system was used for additional biochemical tests. Serological classification was carried on in Central Public Health Laboratories / Baghdad.

Saccharomyces boulardii: The probiotic strain was obtained from Ultra-levure-inter flora (Biocodex, Inc. /France).

Antibiotic sensitivity test (qualitative disk method): 13 antibiotic disks (Amoxicillin, Ciprofloxacin, Amoxicillin -Clavulonic acid, Imipenem, Gentamicin, Nirtofurtoin, Ceftriaxon, Tetracyclin, Trimethoprim- Sulfamethaxazole, Naldixic acid, Chloramphenicol, Ampicillin, Cephalothin) were used to detect the sensitivity of Salmonella isolates [11]. The test was carried on by culturing bacteria at 37C for $18 \mathrm{hr}$ and suspended, homogenized in normal saline and compared with 0.5 standard MacFarland solution and the suspension was cultured on Muller- Hinton agar. The results were compared with National Committee for Clinical Laboratory Standard [11].

\section{Detection of surface hydrophobicity of Salmonella}

Cell surface hydrophobicity of the bacteria was determined by using Bacterial Adhesion To Hydrocarbons (BATH) test [12]. The bacteria were grown in tryptic soy broth at $37 \mathrm{C}^{\circ}$ for $18 \mathrm{hr}$. The Optical Density (OD) was adjusted to 1 at $600 \mathrm{~nm}$. Xylene was added and mixed with the suspension using the vortex; the aqueous phase was taken by using Pasteur pipette. Hydrophobicity was calculated as following:

Hydrophobicity $=\left[\right.$ O.D $D_{\text {initial }}-$ O.D aqueous phase $_{\text {O.D }}$ initial $] \times 100$

Extraction and purification of Surface Layer Proteins (SLP) of S. typhimurium

The extraction was done by using the modified Sarkosyl method [13] which includes obtaining overnight culture of bacteria harvested and resuspended in PBS and then treated with bovine deoxyribonuclease, sonicated and centrifuged, supernatant was taken and recentrifuged at $10000 \mathrm{r} / \mathrm{min}$ for $1 \mathrm{hr}$. The pellet was treated with $2 \%$ 
sakosyl dissolved in $50 \mathrm{mM}$ - Tris $\mathrm{HCl}$ and treated further with $10 \mathrm{mM}$ - Tris $\mathrm{HCl}$ containing 2\% Sodium Dodcyl Sulfate (SDS). The suspension was collected and assessed for protein content.

Detection of surface layer proteins as agglutinins by haemagglutination

The test was carried on by mixing $25 \mu \mathrm{L}$ of extracted SLPs with $25 \mu \mathrm{L}$ of $10 \%$ human erythrocytes which were suspended with or without $0.5 \%$ mannose solution on a glass slide [4].

\section{Detection of Type-1 pili in S. typhimurium}

This test was performed by using two methods:

1. Agglutination with human RBCs (Haemagglutination) :

The test was done as described previously [4] by mixing $25 \mu \mathrm{L}$ of bacterial broth with $25 \mu \mathrm{L}$ of $10 \%$ human erythrocytes on a glass slide; the agglutination was examined visually and microscopically.

2. Agglutination with $S$.boulardii :

Yeast was cultured separately in a medium (2\% peptone, $1 \%$ yeast extract, $2 \%$ glucose) with shaking for $18 \mathrm{hr}$. at $37 \mathrm{C}^{\circ}$, centrifuged and resuspended in PBS and were treated with gluteraldehyde and stained with safranine, the agglutination was proceeded as described previously by mixing bacteria with yeasts [14].

Inhibition of the adhesion of $S$. typhimurium by $S$. boulardii on human buccal epithelial cells

1. Preparation of S. typhimurium and S. boulardii suspensions

Microbial suspensions were prepared by centrifugation overnight of microbial growth in BHI broth, the microbial cells number was adjusted to $1 \times 10^{8}$ cell $/ \mathrm{ml}$ by using viable count method[15].

2. Preparation of buccal epithelial cells

This step was carried on by taking a sterile cotton swab, scraping it on the walls of the buccal cavity suspending and washing by PBS the suspension three times by using centrifugation in $2000 \mathrm{r} / \mathrm{min}$ for $5 \mathrm{~min}$ [16]. The number of the epithelial cells was adjusted to $1 \times 10^{5}$ cell $/ \mathrm{ml}$ by using haemocytometer.

3. Testing the ability of. $S$. typhimurium and $S$. boulardii to adhere This step was carried on by taking $0.5 \mathrm{ml}$ of each microbial suspension prepared previously and mix it separately with $0.5 \mathrm{ml}$ of epithelial cells suspension and incubated with shaking (70 $\mathrm{r} / \mathrm{min}$ ) at $37 \mathrm{C}$ for $60 \mathrm{~min}$, the resulting suspension was washed and resuspeded by centrifugation (2000 r/min) by PBS [16]. One drop was transferred to a clean slide, fixed with methanol then stained by Geimsa stain. Microbial cells that adhered on 50 epithelial cells were counted and their average was calculated.

4. Testing the ability of $S$. boulardii to inhibit the adhesion of $S$. typhimurium This step was carried on as described previously [15] by mixing equal volumes of both microbes with epithelial cells (all prepared previously). Inhibition of the adhesion of $S$. typhimurium by $S$. boulardii was calculated as the following:

Inhibition of adhesion rate $\%=[$ (average of Salmonella adhesion - its' adhesion in the presence of Saccharomyces) / average of Salmonella adhesion] $\times 100$. 


\section{Results and discussion}

\section{Isolation and characterization of Salmonella}

10 isolates diagnosed as Salmonella depending on their biochemical tests which were mentioned previously [10] and the results were confirmed by applying APi 20E system. The ten isolates of Salmonella were tested to identify the serotypes to which they belonged to as its' elucidated in Table (1).

Table (1): Serotypes of Salmonella

\begin{tabular}{ccc}
\hline Isolates & Serotype & Source of Isolation \\
sal 1 & S.ependroff & stool \\
sal 2 & S.muenchen & stool \\
sal 3 & S.enteritidis & stool \\
sal 4 & S.typhi & blood \\
sal 5 & S.enteritidis & stool \\
sal 6 & S.enteritidis & stool \\
sal 7 & S.typhi & blood \\
sal 8 & S.enteritidis & stool \\
sal 9 & S.anatum & stool \\
sal 10 & S.typhimurium & stool \\
\hline
\end{tabular}

\section{Antibiotic sensitivity test of Salmonella}

As it is shown in Figure (1), the highest sensitivity of salmonella isolates was observed towards: imipenem $(100 \%)$ and chloramphinicol $(100 \%)$, trimethoprimsulfamethaxazol (90\%) followed by tetracycline $(80 \%)$ and $(80 \%)$ for ciprofloxacin. A study showed the sensitivity towards chloramphinicol and trimethoprimsulfamethaxazol was (90\%), and it also showed that imipenim was the only effective agent to treat multidrug resistant Salmonella [17]. The results showed that all isolate $(100 \%)$ were resistant to amoxicillin-clavulonic acid, $10 \%$ sensitive to naldixic acid, $70 \%$ sensitive to cephalothin, $60 \%$ sensitive for ampicillin and gentamicin. It was also observed that $30 \%$ of the isolates were sensitive to amoxicillin and ceftriaxon and $10 \%$ were sensitive to nitrofurantoin. The isolate sal 10 which belongs to the serotype $S$. typhimurium was resistant to penicillins (ampicillin and amoxicillin) and $\beta$ lactamase inhibitors combinations (amoxicillin - clavulonic acid) and also resistant to cephalosporins (cephalothin, ceftriaxon) This is due to the production of extended spectrum $\beta$ - lactamases, such $\beta$ - lactamases were described in Salmonella [18]. It was observed an emergence of resistance to ciprofloxacin with isolates sal9 and sal 2. A study reported that resistant strains to ciprofloxacin were shown to have mutations in the production of specific amino acids in specific positions in genome, when imipenem is considered according to results to be effective to Salmonellosis treatment, imipenem resistant Salmonella isolates have already been reported since 1997 [17]. 


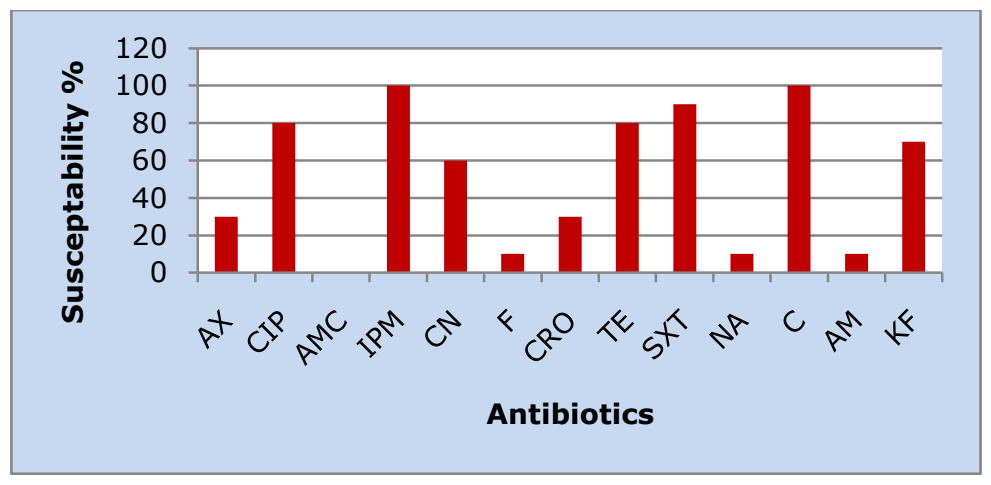

Figure (1): Susceptibility Percentages of Salmonella Isolates for Antibiotics

AX :Amoxicillin, CIP:ciprfloxacin, AMC:amoxicillin- clavulonic acid, IPM:imipenem, CN:gentamicin, F: nitrofuratoin, CRO : ceftriaxone, TE: tetracycline, SXT: trimethoprimsulfamethaxazole, NA:naldixic acid, C:chloramphinicol ,AM:ampicillin,KF:cephalothin

\section{Detection of surface hydrophobicity of Salmonella}

As it is represented in Table (2), the hydrophobicity percentages ranged between $21-$ $90 \%$, the isolates with their hydrophobicity more than $40 \%$ are considered hydrophobic [3]. The most hydrophobic isolates were sal 7and sal 10. Xylene was used instead of aliphatic hydrocarbons such as hexadecane, n-octane because it is negatively charged when it is in contact with aqueous solutions including PBS and can detect the less hydrophobic cells [3] Figure (2). In a previous study reported that physiochemical properties (including hydrophobicity) play a major role in initial interaction with host tissue, on the other hand it was found the presence of a relationship between hydrophobicity of Salmonella and its' virulence [12]. Therefore there had been attempts to lower the hydrophobicity of Salmonella as a method to decrease its' adhesion on surfaces either by using sub inhibitory concentrations of antibiotics, or by adding hydrophilic groups or minerals [19].

Table (2): Hydrophobicity \% of Salmonella isolates measured at wave length $600 \mathrm{~nm}$

\begin{tabular}{cccc}
\hline Isolates & $\begin{array}{c}\text { Initial Optical } \\
\text { Density }\left(\text { O.D }_{\text {initial }}\right)\end{array}$ & $\begin{array}{c}\text { Aqueous phase Optical } \\
\text { Density }\end{array}$ & $\begin{array}{c}\text { O.D aqueous } \\
\text { phase })\end{array}$ \\
sal 1 & 1 & 0.74 & 26 \\
sal 2 & 1 & 0.61 & 39 \\
sal 3 & 1 & 0.66 & 34 \\
sal 4 & 1 & 0.49 & 51 \\
sal 5 & 1 & 0.41 & 59 \\
sal 6 & 1 & 0.76 & 24 \\
sal 7 & 1 & 0.1 & 90 \\
sal 8 & 1 & 0.79 & 21 \\
sal 9 & 1 & 0.5 & 50 \\
sal 10 & 1 & 0.2 & 80 \\
\hline
\end{tabular}

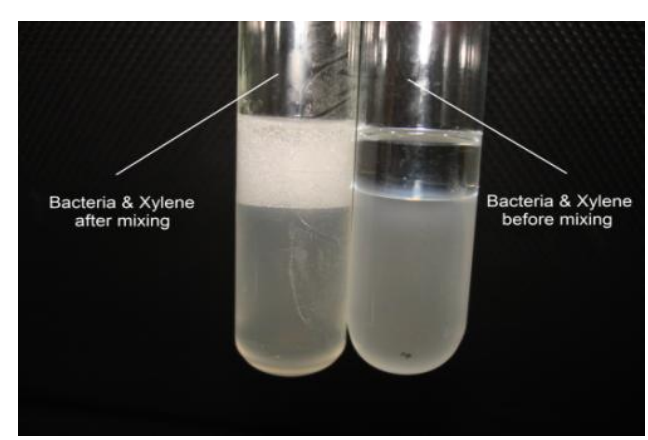

Figure (2): Hydrophobicity Detection Test for Salmonella 
Detection of surface layer proteins as agglutinins by haemagglutination Many investigations had been done upon Salmonella serotype Typhimurium in terms of pathogenesis in comparison with other serotypes [2], so the isolate sal 10 was taken to study its' surface characteristics.

Protein content of the surface layer extract was $0.213 \mu \mathrm{g} / \mathrm{ml}$. The ability of extracted Surface Layer Proteins (SLP) of sal10 to act as agglutinins was observed.

In Salmonella, these proteins play an important role in adhesion by acting as adhesins and by possessing mannose sensitive and mannose resistant molecules; SLPs are also required in invasion of the bacteria [20,21]. SLPs are present in all Salmonella species (motile and non motile) and have an antigenic properties [13]. This explains the ability of S. typhimurium mutants lacking motility and non fimbriated to remain virulent, these mutants have low levels of adhesion to mucosal surfaces but in contrast they remain virulent, this suggests that there are another factors contribute in adhesio (have receptors on mammalian cells) and responsible of virulence [20].

\section{Detection of Type-1 pili in S. typhimurium}

Type -1 pili test showed the ability of Salmonella cells to agglutinate with either human erythrocytes and $S$. boulardii cells and its' inhibition in the presence of mannose. This suggests that Salmonella possesses type 1 pili (mannose sensitive) and this explains the inhibition of its' agglutination when mannose was

added Figure (3). This fact agrees with a previous study [14].This type of pili mediates the attachment of bacteria to mannose which enter in the structure of mammalians cell wall [4]. Also as units known as mannans in the yeasts cell wall [22].

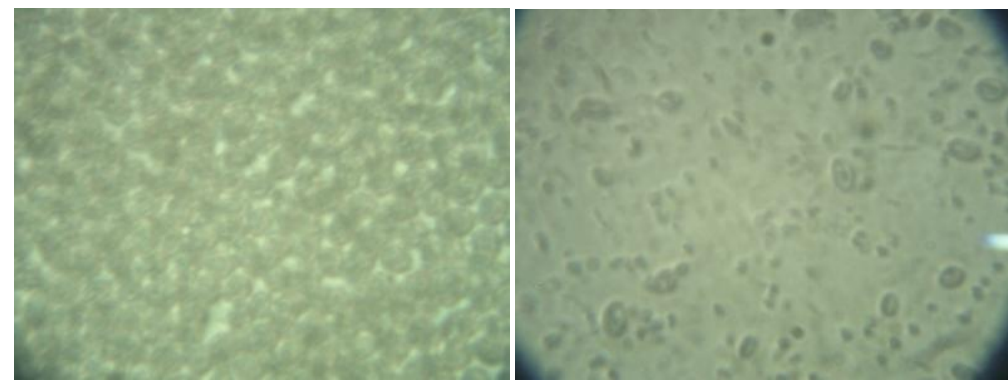

A: without mannose

B: with mannose

Figure (3): Haemagglutination Test of Salmonella Isolate ( sal 10)

Inhibition of the adhesion of $S$. typhimurium by $S$. boulardii on human buccal epithelial cells

Adherence of pathogenic bacteria to host cells is an important step in virulence, the adhesion of pathogenic bacteria to the gut epithelium is an obligatory step in the infection process [15]. The adhesion average of S.typhimurium was 52 cell / epithelial cell whereas the adhesion average of S.boulardii was 20 cell / epithelial cell. The adhesion average of both microbes is considered as a good adhesion [15].

In the presence of $S$. boulardii, it had been observed a decrease in the adhesion average of the bacteria to reach 24 cell/ epithelial cell, in another word $54 \%$ of the bacterial adhesion had been inhibited by S. boulardii (Fig. 4).

$S$. boulardii has been used in the treatment of different types of diarrheal diseases such as antibiotic - associated diarrhea, traveler diarrhea, acute gastroenteritis and 
chronic diarrhea in HIV patients, the mechanism of action of $S$. boulardii in experimental infections had been extensively studied in both animals and invitro assays, these studies indicated that $S$. boulardii may have a protective role and specific activities against various enteric pathogens [23]. The protective role of $S$. boulardii was investigated in previous study against $S$. typhimurium and Shigella flexneri in mice, mortality and histipathology revealed a protective effect in yeast treated mice, it was hypothesized that yeast and the bacteria compete for the same adhesion sites [23].

S.boulardii also has many other protective effects such as: delaying the host cell apoptosis of bacteria by decreasing $50 \%$ of the number of intracellular bacteria and the changes in the cytoskeleton of the epithelial cells [24]. It was found that Saccharomyces was able to colonize and survive in the gastrointestinal tract of germ free mice and also protect the animals against oral infection with S.typhimurium [22].The ability of S.boulardii to agglutinate with cells of S.typhimurium is considered as a protective mechanism against the infection by this pathogen, detection of lectin sites for mannose sensitive adhesion on the outer membrane of the yeast and the irreversible binding pathogens and provides a substitute for drugs used in the treatment of enteric pathogens [25]. As it is mentioned previously D- mannose had been found to be an effective inhibitor of the bacterial adherence. S.boulardii cells contains mannose in their cell wall, this mannose may act as an alternative for the attachment of pathogens [25].

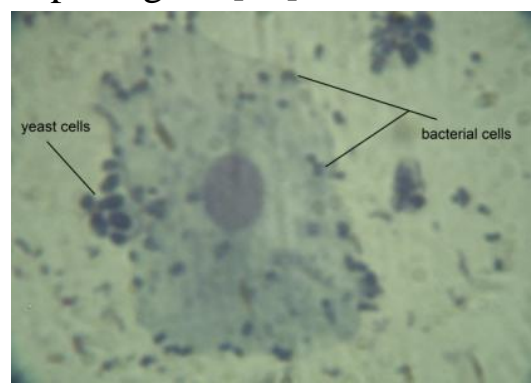

A:adhesion of S.typhimurium in the presence of S.boulardii

Figure (4): Inhibition of The Adhesion of S.typhimurium by S.boulardii

\section{Reference}

1. Brook, G.F.; Carroll, K.C.; Butel, J.S.; and Morse,S. A. (2007). Medical Microbiology $24^{\text {th }}$ (ed.).The McGraw -Hill Companies, Inc.

2. Darwin, K.H.; and Miller,V.L. (1999). Molecular basis of the interaction of Salmonella with the intestinal mucosa. Clin. Microbiol. Rev., 12:405-428.

3. Boris, S.; Suarez, J.E.; Vasquez, F; and Barbes, C. (1998). Adherence of human vaginal Lactobacilli to vaginal epithelial cells and its' interaction with uropathogens. Infect. Immun., 66(5):1985-1989.

4. Sabet, M.; Lee, S.W.; Nauman, R.K.; Sims, T.; and Um, H.S. (2003). The Surface SLayer is a Virulence Factor of Bactroides Forsythus. Microbiology, 149:3617-3627.

5. Drudy, D.; Calabi, E.; Kyne, L.; Sougioultzis, S.; Kelly, E.; Feirweather, M.; and Kelly, C.P. (2004). Human Antibody Response to Surface Layer Proteins in Clostridium Difficile Infection. FEMS Immunol. Med. Microbiol., 41:237-242. 
6. Brisabois, A.; Cazin, I. ; Breuil,J.; and Collatz, E.(1997). Surveillance of antibiotics resistance in Salmonella. Eurosurveillance. 2(3).

7. Fooks , L.J.; and Gibson, G.R. (2002). Probiotics as modulators of the gut flora. Brit. J. Nutr. 88(1):39-49.

8. Sazawal, S.; Hiremath, G.; Dhingra, U.; Malik, P.; Deb,S.; and Black, R.E. (2006). Efficacy of probiotics in prevention of acute diarrhea: a meta - analysis of masked, randomized, placebo- controlled trials. Lancet Infect. Dis. 6:374-382.

9. Moslehi- Jenabian, S.; Pedersen, L.L.; and Jespersen, L. (2010). Beneficial effects of probiotics and food borne yeasts on human health. Nutrients. 2:449-473.

10. Collee, J.G.; Miles, R.S.; and Watt, B. (1996).Tests for the identification of the bacteria. In: Mackie and MacCartney Practical Medical Microbiology by Collee, J.G; Fraser, A.G.; Marmion,B.P. ; and Simmon, A. $14^{\text {th }}$ (ed.) .Churchill Livingstone.

11. NCCLS. (2002). Performance Standards for Antimicrobial Susceptibility Testing; Twelfth Informational Supplement. National Committee for Clinical Laboratory Standards. 22(1): 1-130.

12. Ngwai, Y.B.; Adachi, Y.; Ogawa,Y.; and Hara, H. (2006). Characterization of biofilm - forming abilities of antibiotic resistant Salmonella typhimurium DT104 on hydrophobic a biotic surfaces. J.Microbiol. Immunol. Infect. 39: 278-291.

13. Jaradat, Z.W.; and Zawistowski, J. (1998). Antigenically stable $35 \mathrm{KDa}$ outer membrane protein of Salmonella. Food Agricult. Immunol. 10:259-270.

14. Mirelman, D.;Altmann, G.; and Eshdat, Y. (1980). Screening of Bacterial Isolates for Mannose-Specific Lectin Activity by Agglutination of Yeast. G.Clin.Microbiol. 11(4):328-331.

15. Reid, G.; Cook, R.L.; and Bruce, A.W. (1987). Examination of strains of Lactobacilli for properties that may influence bacterial interference in the urinary tract. G.Urol. 138:330-335.

16. Shibil, A.M. (1985). Effects of antibiotic on the adherence of Microorganisms epithelial cells. Rev. Infect. Dis. 7(1):15-20.

17. Chiu, C.H.; Wu,T.L.; Su, L.H.; Chu, C.; Chia, J.H. Kuo, A.J.; Chien, M.S.; and Lin T.Y. (2002). The emergence in Taiwan of fluoroquinolone resistance in Salmonella enterica serotype Choleraesuis: N.Engl.J.Med. 346:413-419.

18. Chu, C.; Chiu, C.H.; Wu, W.Y.; Chu,C.H.; Liu, P.T.; and Ou, J.T. (2001). Large drug resistance virulence plasmids of clinical isolate of Salmonella enterica serotype Choleraesuis. Antimicrob. Agents Chemother. 45:2299-2303.

19. Ukuku, D.O.; and Fett, W.F. (2006). Effect of cell surface charge and Hydrophobicity on attachment of 16 Salmonella serovars to cantaloupe rind and decontamination with sanitizers. J. food Protect. 69(8):1835-1843.

20. Hayward, R.D.; Mcghie, E.J.; and Koronakis, V. (2000). Membrane Fusion Activity of Purified SipB a Salmonella Surface Protein Essential for Mammalian Cell Invasion. Molec. Microbiol. 37(4):727-739.

21. Hahn, H.P.; and Von Specht, B.U. (2006). Secretory delivery of recombinant proteins in attenuated Salmonella strains: potential and limitation of type 1 protein transporters. FEMS Immunol. Med. Microbiol. 37(3):87-98. 
22. Martins, F.S.; Rodrigues, A.P.; Tiago, F.C.P.; Penna, F.J.; Rosa, C.A. ; Arantes, R.M.E.; Nardi, R.M.D.; Neves, M. J.; and Nicoli, J.R. (2007). Saccharomyces cerevisiae strain 905 reduces the translocation of Salmonella enterica serotype Typhimurium and stimulates the immune system in gnotobiotic and conventional mice. J. Med. Microbiol. 56 :352-359.

23. Czerucka, D.; and Rampal, P. (2002). Experimental effects of Saccharomyces boulardii on diarrheal pathogens. Microb. Infect. 4(7): 733-739.

24. Czerucka, D.;Dahan, S.; Mograbi, B.; Rossi, B.; and Rampal, P. (2000). Saccharomyces boulardii preserves the barrier function and modulates the transduction pathway induced in Enteropathogenic Escherichia coli - infected T84 cells .Infect. Immun. 68:5998-6004.

25. Gedek, B.R.; Sachverst,C.; Agndige, F.C.; and BcrMirko, C. (1999). Adherence of Escherichia coli serogroup O157 and the Salmonella tphimurium mutant DT 104 to the surface of Saccharomyces boulardii. Mycoses. 42(4):261-264. 